\title{
Colonoscopy and Microscopy: Two sides of the coin- Our experience at Tertiary Care Centre in Central India
}

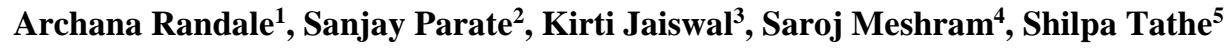 \\ ${ }^{1,4,5}$ Assistant Professor, ${ }^{2}$ Professor \& HOD, ${ }^{3}$ Associate Professor, Dept. of Pathology \\ *Corresponding Author: \\ Email: drarchanarandale@gmail.com
}

\begin{abstract}
Introduction: The colonoscopy along with mucosal biopsy interpretation forms a prime diagnostic tool in work of patients with lesional diversity of colorectal region. The study was conduted to evaluate the histomorphological spectrum of colorectal lesions on colonoscopic biopsies and correlate the microscopy (histomorphology) with colonoscopic diagnosis offered.

Materials and Methods: The material consisted of 168 colonoscopic biopsies which were submitted to the Department of Pathology, Govt. Medical College \& Superspeciality Hospital, Nagpur during the period of Jan 2014 -Dec 2016. The histopathological classification of these lesions was based on WHO. Statistical analysis was done by Open Epi Info software.

Result: Out of 168 colonoscopicbiopsies, 116 were non-neoplastic and 52 were neoplastic. A higher frequency of colonic diseases occur in males with male: female ratio -1.4:1 and the age range was between 2 yrs to 92 yrs. Among the non-neoplastic lesions, ulcerative colitis was most common diagnosis, with frequent age group involved was 41- 50 yrs. Uncommon but interesting lesions like amoebic colitis ( 2 cases), pseudo membranous colitis( 1 case), Melanosis coli (1 case) \& congestive colopathy (1 case) were also found. Hyper plastic polyp \& retention polyps were most common in non-neoplastic category while villous adenoma with dysplasia's was most common in neoplastic polyps. Among the neoplastic lesions, conventional adenocarcinoma was the commonest subtype with rectum as the most common site.

Conclusion: Colonoscopy \& Microscopy are the two sides of the coin which can be used effectively together not only in diagnosis \& treatment of colorectal lesions but alsosurveillance of inflammatory bowel disease. As $48 \%$ of overall malignant lesions occurred in less than 50yrs of age, due importance should be given to colonoscopic screening to detect early colorectal neoplasm.
\end{abstract}

Keywords: Colonoscopy, Colorectal carcinoma, Dysplasia, Microscopy (histomrphology), Ulcerative colitis, Villous adenoma.

Received: $02^{\text {nd }}$ May, 2017

Accepted: $13^{\text {th }}$ September, 2017

\section{Introduction}

India is a country with cultural diversity and so the variable dietary habits. ${ }^{1,2}$ Similar diversity is seen in spectrum of colorectal lesions ranging from infectious, inflammatory diseases, polyps and colorectal tumors. ${ }^{1,3-4}$ With passing generations and changing lifestyle there is an increase in the incidence of gastrointestinal disease. $^{5}$ But with the advent of flexible endoscope, it is possible to view all portions of large intestine \& rectum. ${ }^{1,6-8}$ The colonoscopy with accompanying mucosal biopsy evaluation is the prime diagnostic tool in work up of patients with lesional diversity of colon \& rectum. ${ }^{9}{ }^{9}$ So the study was undertaken with the following objectives to study histomorphological spectrum of colorectal lesions on colonoscopicbiopsies .and to correlate microscopy (histomorphology) with colonoscopic diagnosis offered. An attempt was also made to comment on severity and extent of colonic lesions wherever possible by histomorphological examination. 


\section{Results}

A total of 168 colonic biopsies were obtained over the span of three years. Our study had higher frequency of colorectal lesions in males with male to female ratio of 1.4: 1 . Biopsies were performed on all the age groups, with the youngest being 2 years and oldest of 92 years. The biopsies were categories as nonneoplastic (116) and neoplastic lesions (52).

The lesional spectrum of non-neoplastic inflammatory cases is shown in Table (I). Ulcerative colitis (35.5\%) was found as most common non-neoplastic lesion with the age group most commonly involved was $41-50$ years followed by proctitis.

Table 1: Shows distribution of Inflammatory Non-neoplastic Colorectal lesions

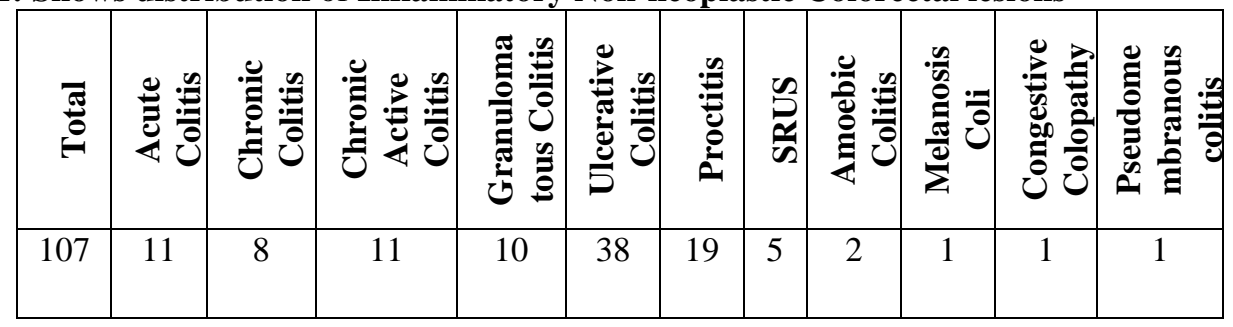

Total 20 colorectal polyps were studied among which neoplastic polyps were more common than the non-neoplastic one. Among non-neoplastic polyps $(n=9)$ we had inflammatory polyp $(n=1)$, hamartomatous polyp $(n=2)$, retention \& hyperplastic polyp 3 cases each .Distribution of neoplastic polyps is shown in table 2 .

Table 2: Shows distribution shows distribution of Neoplastic polyps

\begin{tabular}{|l|c|c|}
\hline \multicolumn{1}{|c|}{ Neoplastic polyp } & $\begin{array}{c}\text { Without } \\
\text { dysplasia }\end{array}$ & $\begin{array}{c}\text { With } \\
\text { dysplasia }\end{array}$ \\
\hline Tubular Adenoma & $1(5 \%)$ & - \\
\hline Tubulovillous Adenoma & $1(5 \%)$ & $4(20 \%)$ \\
\hline Villous Adenoma & - & $5(25 \%)$ \\
\hline Total(11) & 2 & 9 \\
\hline
\end{tabular}

We had total of 41 malignant cases detected on histopathology with male to female ratio among the cancer group was 1.1:1. The distribution of malignant lesions is summarized in Table 3

Table 3: Distribution of malignant lesions

\begin{tabular}{|l|c|c|c|c|}
\hline Age group & Adenocarcinoma & $\begin{array}{c}\text { Mucinous } \\
\text { Carcinoma }\end{array}$ & $\begin{array}{c}\text { Signet ring } \\
\text { carcinoma }\end{array}$ & $\begin{array}{c}\text { Neuroendocrine } \\
\text { Carcinoma }\end{array}$ \\
\hline & M F & M F & M F & M F \\
\hline $0-10$ & -- & & & \\
\hline $11-20$ & -- & 1 & & \\
\hline $21-30$ & -1 & 1 & 1 & \\
\hline $31-40$ & 31 & & & \\
\hline $41-50$ & 63 & 11 & & \\
\hline $51-60$ & 23 & & & \\
\hline $61-70$ & 67 & & & \\
\hline $71-80$ & 21 & & & \\
\hline $81-90$ & -- & & & 1 \\
\hline & 1916 & 22 & 1 & $1(2.4 \%)$ \\
\hline Total (41) & $35(85.5 \%)$ & $4(9.75 \%)$ & $1(2.4 \%)$ & \\
\hline
\end{tabular}

The most common age group affected by was $61-70$ yrs. The patients were broadly classified into younger $(<50 \mathrm{yrs})$ and older $(>/=$ $50 \mathrm{yrs})$ age group. In our study $48 \%$ patients were $<50 \mathrm{yrs}$.
In our study rectum was most common site for malignant lesions $63.41 \%$ followed by right sided colon $31.7 \%$ and left sided colon $4.8 \%$.

The statistical analysis was done by Open EpiInfo software for comparing the diagnosis offered by colonoscopy with microscopy 
(histomorphology) as a gold standard .Result: (95\% CI)

1. Sensitivity $-75.95 \%(68.72-81.95 \%)$

2. Specificity $-10 \%(1.79-40.42 \%)$

3. Positive predictive value $-93.02 \%$ (87.27$96.29 \%)$

4. Diagnostic Accuracy - $72.02 \%$ (64.8$78.26 \%)$

5. McNemar's Chi-Square $(\mathrm{df}=1) \mathrm{p}=0.0001$

\section{Discussion}

Lesional spectrum of colorectal lesions can be very well visualized with flexible (fibro-optic) endoscope which is a establish diagnostic procedure of choice in the clinical settings of chronic diarrhea, constipation, abdominal pain \& bleeding P/R. ${ }^{1}$ But with the nonspecific symptomatology \& colonoscopy mimics, colonic biopsy \& thereby histomorphology is required for accurate \& confirmative diagnosis. ${ }^{1,9,10}$

We studied total 168 colonoscopic biopsies during three years span, of which non-neoplastic were $69 \%$ and neoplastic $31 \%$. Our findings correlated well with Pandey et al, Rangaswamy et al \& Rajbhandari et al. ${ }^{1,9,11}$

Among non-neoplastic lesions, ulcerative colitis (Fig. 1) (38 cases) was the most common diagnosis in our study (Fig. 1). However Pandey et al, Rangaswamy et al \& Rajbhandari et al. ${ }^{1,9,11}$ showed chronic colitis as the most frequent diagnosis. But according to Puri et al, Ray et al \& Azad et al, ${ }^{12-14}$ incidence \& prevalence of ulcerative colitis is on rise in Indian subcontinent with shifting of non-neoplastic colorectal lesions from infectious to non-infectious life style diseases in last 40 years $^{12-14}$ justifying our findings.

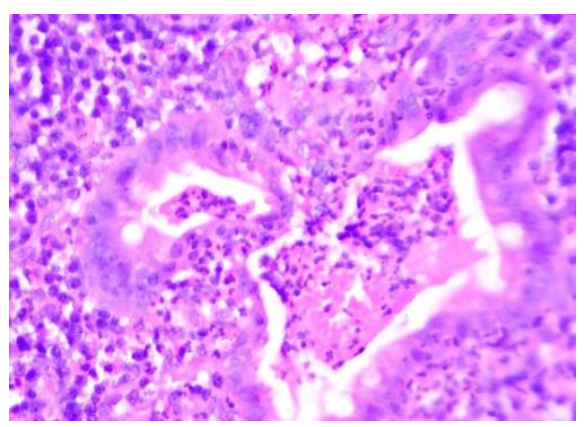

Fig. 1: Section showing -Intraepithelial neutrophils, crypt abscess \& crypt deformity in Ulcerative colitis $(\mathrm{H} \& \mathrm{E}, \mathrm{x} 200)$

Disease prevalence of ulcerative colitis in our was highest in $41-50$ years of age $e^{1,15,16}$ with pancolitis the most common colonoscopic diagnosis which mirrors the finding of other authors. ${ }^{17}$
Colonoscopy with accompanying biopsy has a crucial role in surveillance of ulcerative colitis $^{15,18}$ to reduce the risk of colorectal cancer. We had reported dysplasia in three cases of ulcerative colitis in follow up biopsies. (Fig. 2)

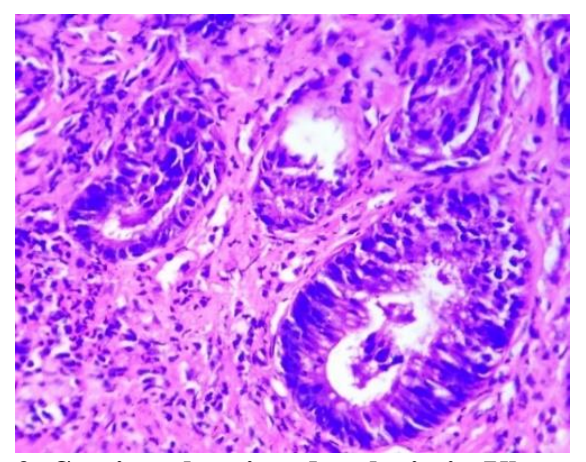

Fig. 2: Section showing dysplasia in Ulcerative colitis $(\mathbf{H} \& \mathrm{E}, \mathrm{x} 200)$

Tuberculosis is considered as a biggest health crisis confronting India ${ }^{1,11,19}$. Present study encountered with three cases of colonic tuberculosis (Fig. 3) showing multiple, confluent, well-formed granulomas typically congregated in lamina propria \& sub mucosa with focal areas of necrosis in contrast to cryptcentric, ill formed granulomas of Chron's disease. $^{20}$

Among the neoplastic polyps we had villous adenoma \&tubulovillous adenomas with dysplasia's were most common mirrors the result of Rangaswamy et $\mathrm{al}^{9} \&$ contradicting with Konishi et al. ${ }^{21}$ Higher grade dysplasia's reveal nuclear palisadation, occupying more cell length with less mucin production. Variable hyperchromasia with loss of polarity also noted. ${ }^{20}$ Some authors ${ }^{22,2}$ suggest if biopsy is taken from grossly evident mass lesions ,finding any degree of dysplasia deserves consideration for colectomy since such lesions more often have carcinoma.

Total 41 cases of colonoscopic biopsies were diagnosed as malignant of which 37 were conventional adenocarcinoma, mucinous adenocarcinoma $(\mathrm{n}=4)$ (Fig. 3), signet ring carcinoma $(\mathrm{n}=2) \quad$ (Fig. 4) and a well differentiated neuroendocrine carcinoma $(n=1)$ findings analogous to ${ }^{[1,9,11]}$ Rectum was most common site for malignant lesion in our study matching with others. ${ }^{1,3,9,11}$ 


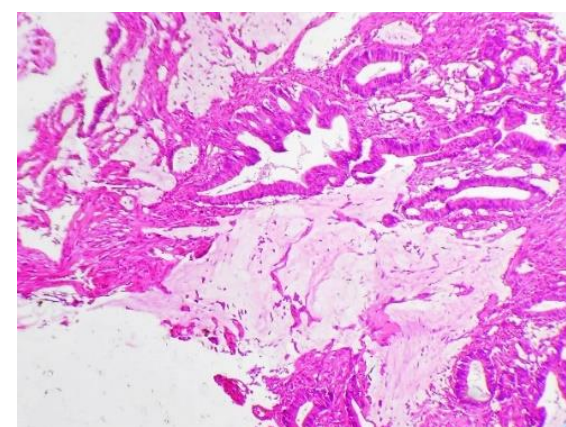

Fig. 3: Section showing Mucinous adenoncarcinoma (H \& E, x 200)

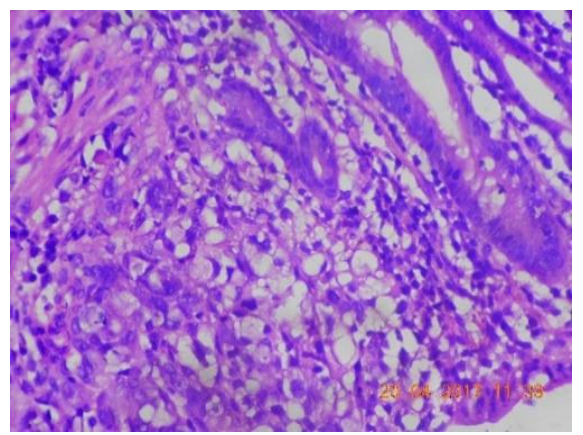

Fig. 4: Section showing Signet ring carcinoma, colon $(\mathbf{H} \& \mathbf{E}, \mathbf{x} 200)$

Regular endoscopic examination in the first year after surgery is important for detection of potentially curable recurrence. ${ }^{24} \mathrm{We}$ had three cases of recurrence of primary tumor at anastomotic site which represents failure cases.

One patient of carcinoma cervix in our study who received pelvic irradiation, developed rectal adenocarcinoma ten years after the radiation exposure, a known complication. ${ }^{25}$

$48 \%$ of overall malignant lesions occurred in $<50$ years of age increasing our worry along with $^{1,11}$ insisting on starting the screening of colorectal malignancies at early age along with life style modification.

\section{Conclusion}

Colonoscopy \& microscopy are the two sides of the coin which can be used effectively together not only in diagnosis \& treatment of colorectal lesions but also in surveillance of inflammatory bowel disease \& screening of colorectal cancer as the positive predictive value was found to be $93 \%$.

\section{References}

1. Shukla MP, Pandey A, Dombale VD. Histomorphological Profile of colonoscopic Biopsies - A two year study in a Tertiary Care Hospital in South India. International Journal of Science and Research 2016;5:1513-18.
2. Sanjay Bandopadhyay Chrons disease: The Indian Perspective. Medicine update, 2012;22:419-25.

3. Chaitanya B, Ramkrishna BA, Shanti V, Reddy SR Microscopy after colonoscopy: An Institutional Experience in India. International Journal of Medicine Research \& review 2014;2:92-97.

4. Singh H, Turner D, XueL, Targownik LE, Bernstein Risk of developing colorectal cancer following a negative colonoscopy examination. CN JAMA 2006;295:2366-73.

5. Soudamini S, Histopathological assessment of colonic biopsy complaining of chronic diarrhoea

6. Hirschowitz B. Development \& application of Endoscopy. Gastroenterology 1993;104:337-42.

7. Teague RH, Salmon PR, Read AE. Fibroptic examination of the colon: A review of 255 case. Gut 1973;14:139.

8. Cappell MS, Friedel D The role of sigmoidoscopy and colonoscopy in diagnosis and management of lower gastrointestinal disorders: endoscopic findings, therapy and complication. Med Clin North Am 2002;86:1258-88.

9. Rangaswamy RL, Sahadev RZ, Suguna BV, Preethan KN, Ranjeeta SB. Clinico-colonoscopic and histomorphological spectrum of colonic diseases in an Academic tertiary care centre: Journal of Evolution of Medical and Dental Sciences 2014;3:1-9.

10. Jeddah. Qayyum A, Sawan. Profile of colonic biopsies in King Abdul Aziz University Hospital. AS.J Pak Med Assoc.2009;59:608-11.

11. Rajbhandari M, Karmacharya A, Khanal K, Dhakalp, Shrestha R: Kathmandu Histopathological profile of colonoscopic Biopsies and Pattern of Colorectal carcinoma in Karve District. University Medical Journal 2013;43:196-00.

12. Singh PA .Epidemiology of Ulcerative Colitis in south Asia. International Research 2013; 11:25055.

13. Gautam R. Inflammatory bowel disease in IndiaPast, present \& future. World Journal of Gastroenterol 2016;28;8123-36.

14. Sheenam A, Sood N, Sood A. Biological \& histological parameters as a predictor of relapses in ulcerative colitis: A prospective study. Saudi J Gastroenterol 2011;17:194-8.

15. Badmapriya D, Kumar VS: Profile of Ulcerative colitis in South Indian Region, Karaikal. IJPBS 2011;1:47-51.

16. Sood A, Vandana M et al Profile of Ulcerative colitis in a North India Hospital: Journal of Indian Academy of clinical Medicine 1998;5:124-28.

17. SivaramG,Santosh K et al: The epidemiology and prevalence of ulcerative colitis in the south India: Open Journal of Immunology 2012;2:144-48.

18. Endoscopy in Inflammatory bowel disease. In: kirsner JB, ed Inflammatory bowel disease. $5^{\text {th }}$ ed.Baltimare: Williams \&Wilbins; ChutkanRK \& Waye JD:2000;453-777.

19. 19.Intestinal tuberculosis in a regional hospital in Hong Kong :A 10 years' experience in a regional hospital :Leung VKs ,Law St,Lam CW et al: Hong Kong Med J 2006;12:264-71

20. Harvey Goldman, Jihad Hayek. Gastrointestinal mucosal biopsy, Inflammatory Disorders of colon 
\& rectum: Contemporary issues in surgical pathology 1996;20;377-71.

21. Konishi F, Morson BC. Pathology of colorectal adenoma: acolonoscopicsurvey. J Clin Pathol 1982;35:830-41.

22. BlackstoneMO, RiddellRH, Rogers RHG et al Dysplasia associated lesion or mass (DALM) detected by colonscopy in long standing ulcerative colitis: an indication for colectomy. Gastroenterology 1981;80:366.

23. Woolrich AJ, Dasilva MD, Korelitz B Surveillance in the routine mgt of ulcerative colitis: the predictive value of low grade dysplasia. Gastroenterology 1992;103:431-38.

24. Buhler H, Seefeld U, Deyhle P, Buchmann P, Metzger U, Amman R. .Endoscopic follow up after colorectal cancer surgery. Early detection of local recurrence. Cancer 1984;54:791-93.

25. Black WC, Ackerman LA Carcinoma of large intestine as a late complication of pelvic radiotherapy. Clinicalradiol 1965;16:278- 81 . 